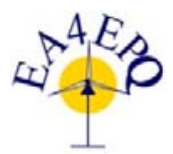

International Conference on Renewable Energies and Power Quality

(ICREPQ'13)

Bilbao (Spain), $20^{\text {th }}$ to $22^{\text {th }}$ March, 2013

Rencurable Encrgy and Poume Quatily foumat (RE\&PQJ)

ISSN 2172-038 X, No.11, March 2013

\title{
A New, Ultra-Low-Cost Power Quality and Energy Measurement Technology Bringing SmartGrid on the Factory and Automation Floor
}

\author{
A. Alex McEachern ${ }^{1}$, B. Andreas Eberhard ${ }^{2}$ \\ Power Standards Lab (US) \\ Phone: ++1(510)522-4400, Fax: ++1(510)522+4455, Email: alex@powerstandards.com, \\ aeberhard@powerstandards.com
}

\begin{abstract}
This paper introduces a new application for Power Quality and Energy Monitoring: embedding power quality monitors inside sensitive industrial, commercial, automation, manufacturing and medical equipment - and bringing SmartGrid to the factory and automation floor. Using power quality monitors to solve intermittent problems has also been limited by the cost of monitors. In this case, the monitors are generally installed at the equipment terminals. So the monitors can either directly interface with the load, or they can interface via e-mail or WebServer with a remotely connected user. In addition the new technology also combines a high accuracy energy monitor that can precisely control loads based on the load profile.
\end{abstract}

It also introduces IEC 61000-4-30 which is an excellent standard that ensures that all compliant power quality instruments, regardless of manufacturer, will produce the same results when connected to the same signal. However, instruments that comply with the Class A requirements of this standard have, until now, been too expensive for common use. Now a new set of technologies developed by an American company, in cooperation with a Japanese company, demonstrate that it is possible to manufacture three-phase power quality instruments that are fully compliant with the Class A requirements of IEC 61000-4-30, and to do so at ultra-low-cost, allowing these monitoring devices to be used even at entry levels of individual loads.

\section{Keywords}

Power Quality, Instrument, SmartGrid, New Measurement Technology, Meter, Low Cost, Monitoring, PQube, IEC 61000-4-30

\section{Introduction}

Traditionally, power quality instruments have been complex and expensive - often several thousand Euro.

The cost of power quality instruments is driven by five factors:

1. The cost of developing the instruments

2. The quantity of instruments produced - the more instruments that are produced, the lower the development cost in each instrument

3. The cost of manufacturing the instruments

4. The cost of installation, especially the cost of the communication infrastructure

5. The cost of supporting the instruments, especially the cost of supporting specialpurpose software, throughout the life of the instruments.

Remarkably, in the last few years, all of these costs have been driven down simultaneously.

This paper describes the technologies in a new, ultra-low-cost power quality instrument, and explains why the costs are so low.

\section{Reduction in Development Costs}

Traditional power quality instruments were developed, from the start, as special purpose instruments. Hardware, firmware, and software were all developed specifically for that instrument.

However, several developments in other, unrelated industries have made that approach unnecessary. 
First, the wide-spread development of digital audio (mobile phones, mobile music players, digital television, etc.) has led to rapid developments in the DSP (digital signal processor) field. New DSP chips are inexpensive, use minimal power, and have built-in analog-to-digital and digital-to-analog conversion. Best of all, they are optimized for processing multiple channels of $20 \mathrm{~Hz}$ to $20 \mathrm{kHz}$ signals. By coincidence, power quality measurements are generally made between $50 \mathrm{~Hz}$ and $3 \mathrm{kHz}$ - right in the middle of the optimum band. The popularity of the $\mathrm{iPod}^{\circledR}$ has resulted in cheaper, better power quality monitors.

Second, the development of relatively complex portable devices (PDAs, mobile phones that also have computer functions, digital cameras, etc.) means those extremely tiny, highly reliable electronic devices are now readily available: connectors with large numbers of pins, tiny op amps, and passive components like resistors and capacitors. Tiny means cheap, in general, if the manufacturing is completely automatic.

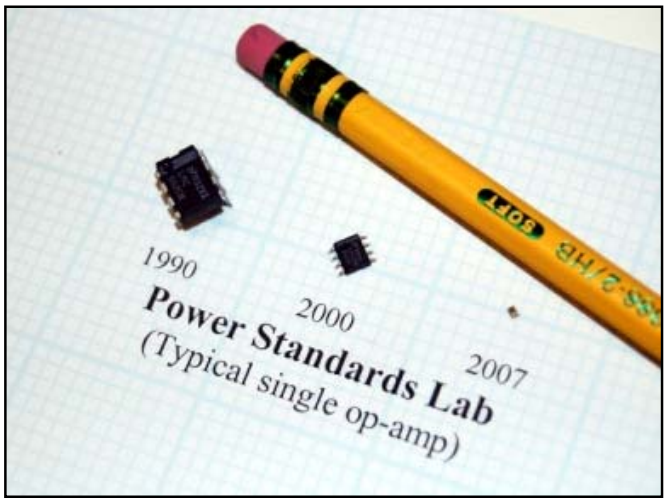

Figure 1: Reduction in component size. Smaller components reduce costs in several ways: smaller printed wiring boards, smaller plastic packages, even smaller power supply requirements. The packages shown are, from left: through-hole DIP, surface mount, and BGA, or ball-grid-array.

Third, the availability of high-voltage $(1 \mathrm{kV})$, low-current op amps, which are generally used for driving submarine sonar transducers, means that automatic test equipment for power quality instruments can be developed far more cheaply now.

Finally, software standards for file structures - as in digital cameras - mean that power quality instrument developers no longer need to define and support their own file structures. In fact, Windows ${ }^{\circledR}$ text files and web-based graphic file formats have become virtually universal.

Of course, some very difficult problems must still be solved by the instrument engineer. How should one deal with a $6 \mathrm{kV}$ lightning impulse in such a tiny package? How can one meet the creepage and clearance requirements in the safety standards? Most important of all, a power quality instrument must, by definition, work when the power is bad, and other electronic devices are failing. How can an engineer design an instrument that survives conditions that other instruments can't? But all of these difficult challenges can be met.

\section{Increase in the quantity of power quality insturments}

Traditionally, each country defined its own power quality instrument requirements. This meant that an instrument optimized for France, for example, was unlikely to find acceptance in Brazil, for example. Sometimes the situation was even worse: each electric power company would define its own requirements for power quality measurements.

As a result, the production quantity for each instrument design was small, and the fraction of the development cost carried in each instrument was large. A rough example: If developing an instrument costs 1.5 million Euros, and the total expected market is 2000 instruments, each instrument must carry 750 Euros of development costs - a significant but not uncommon burden. Recent IEC standards [1][2][3][4] have solved this problem.

IEC 61000-4-30[1][2], in particular, has defined power quality measurement methods. Class A in this standard ensures that any two instruments, when connected to the same signal, will produce the same result. Figure 2 and Figure 3 give examples.

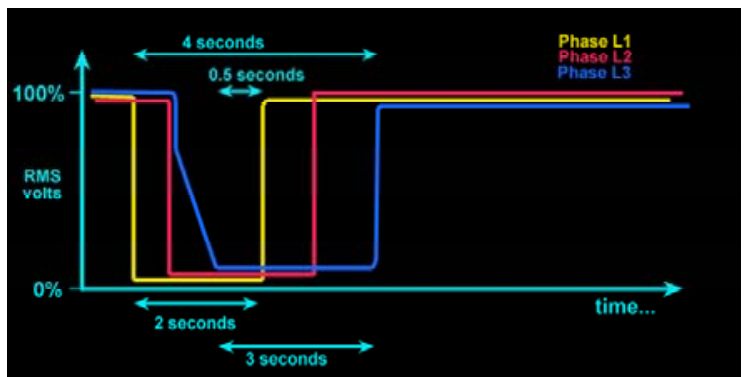

Figure 2. Example of one of the problems solved by IEC 61000-4-30. In this graph of RMS voltages, what is the duration of the voltage dip? The answers shown range from 0.5 seconds to 4 seconds, and all of them are technically correct. Simply by designating one of these answers as the requirement (4 seconds for dip duration measurement, 0.5 seconds for interruption duration measurement), IEC 61000-4-30 reduces cost of instrumentation. 


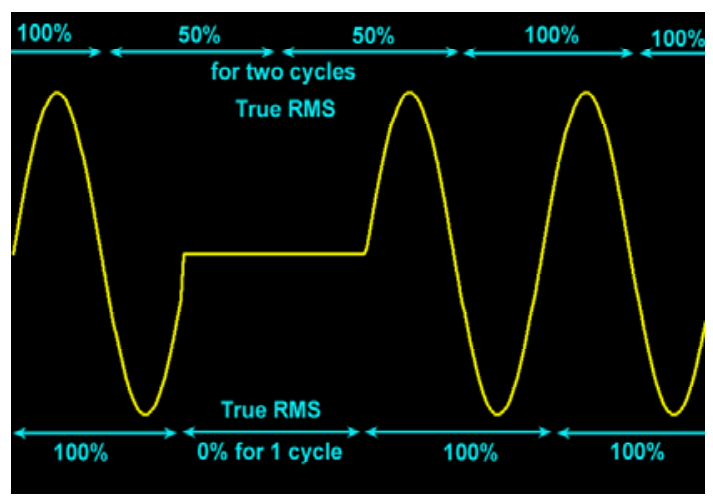

Figure 3. Example of another problem solved by IEC $61000-4-30$. Is this dip $50 \%$ for two cycles, or $0 \%$ for 1 cycle? Again, both answers are technically correct. IEC61000-4-30 makes it clear that this is a dip to $0 \%$ for 1 cycle - thus reducing cost of instrumentation.

As a result of this IEC standardization, an instrument can be designed for worldwide acceptance, allowing much higher total production quantity. This means that the development cost burden is much smaller.

\section{Decrease in Manufacturing Costs}

Globalization has driven manufacturing costs down.

It is now easy to choose the best sources for parts, worldwide. For example, in the initial product shown in Figure 4, the lower case comes from Germany, the upper case comes from the United States, the display and the memory come from Japan, and the internal electronics are automatically assembled in California using parts from the U.S., Ireland, China, Japan, and other countries.

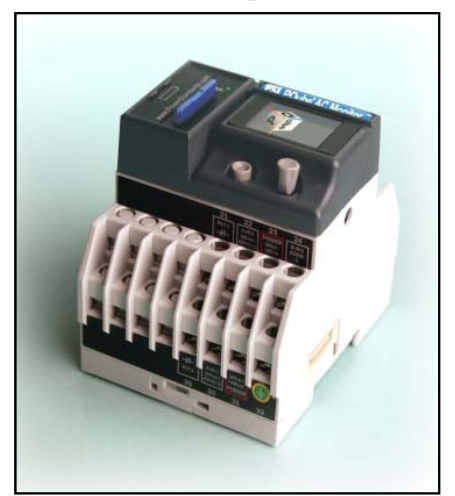

figure 4. Initial Design of a three-phase, voltage-andcurrent, IEC 61000-4-30 Class A-compliant power quality monitor. The digital camera influence can be seen in the SD memory card, which holds up to 4 GB of data. Standard DIN-rail mounting means installation is cheapand quick. The name of this new device: PQube. Power Quality in a little cube.
Fully automated manufacturing (robots for placing parts, automatic testing systems for verifying that boards are working properly, automatic calibration systems that adjust internal digital constants, etc.) means that manufacturing costs can be kept very low, even in locations with high labour costs like California, without any sacrifice in quality. Indeed, the quality of products manufactured in environments with highly automated production and test procedures is generally higher than products that are produced in regions with low labour costs and low automation.

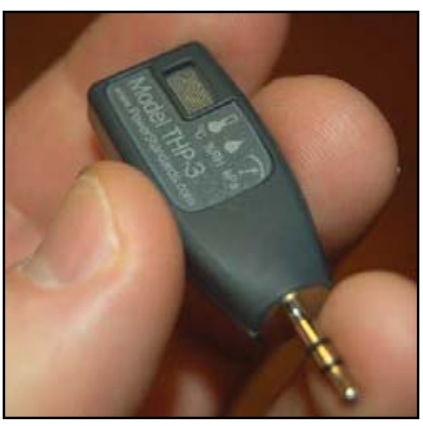

Figure 5. Probes for parameters that may be related to power quality are included in the package: temperature, humidity, barometric pressure, etc. A GPS satellite receiver ensures precise timing.

\section{Decrease in Installation and Communication Costs}

Traditional power quality instruments come with their own unique packaging design. However, they are not always suited for their typical locations, usually where there are low-voltage circuit breakers.

By packaging the power quality instrument in a standard 35mm DIN-rail circuit breaker package, installation is greatly simplified.

Perhaps more important, the communication cost of an installed power quality instrument, over the life of the instrument, often exceeds the cost of the instrument itself. Whether the communication is via Ethernet, or telephone modem, or short-distance radio, bringing the communication signal to the monitoring point is a significant cost.

(We should not forget the additional hidden cost of the damage that can be caused to the communication network during major power disturbances. In regions with strong lightning activity, for example, telephone modems typically become damaged through their connection to power quality monitors.) 
The featured new little product has innovative communication ability. The unit shown in Figure 4 supports Ethernet connectivity (and includes a web server, an FTP server, and an email generator), wireless radio connectivity, and a modem connection. However, it is fully functional without connectivity - it can easily store years of data on a removable SD memory card.

\section{Decrease in the coast of Supporting Power Quality Instruments}

Although it is often hidden from the end user, the lifetime support cost for traditional power quality instruments is significant.

This is especially true for the special-purpose software that was written for each instrument. Often, this software was written for Windows ${ }^{\circledR}$; and the lifetime of a power quality instrument greatly exceeds the lifetime of one release of Windows ${ }^{\circledR}$. For example, many power quality instruments that are still in use were originally issued with Windows ${ }^{\circledR} 3.1$ software.

The lifetime costs of upgrading and supporting this software was a major cost.

Fortunately, such software is no longer necessary. By following the software-free model of a digital camera, the prototype power quality instrument of Figure 4 requires absolutely no software. When you connect a digital camera to your computer, you immediately see the pictures in a folder on your disk drive. The same is true for power quality data in the prototype instrument.

By eliminating the need for any software at all, power quality monitors like the little PQube above drive down the costs even further.

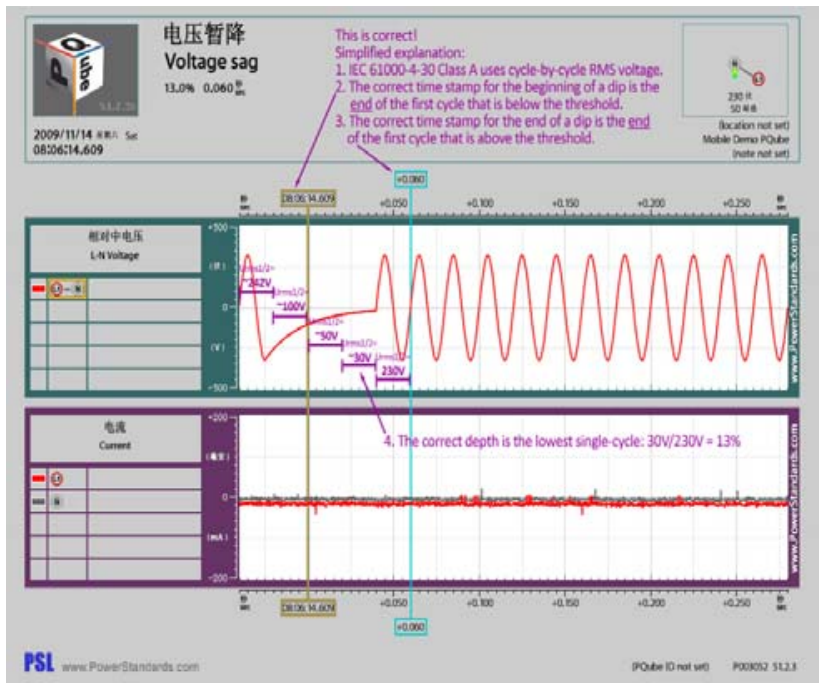

Figure 6. A typical event graph that is generated by the little PQube - Power Quality and Energy Monitor. These kind of graphs are generated without any software. Picture shows typical voltage sag

Again, this does not eliminate all firmware challenges. The instrument firmware must still support a wide variety of languages and character sets (Japanese, Korean, etc.), and the .CSV (comma-separated values) files for spreadsheets must work with European systems that use the comma symbol for other purposes. But all of these problems have been previously solved in digital cameras and the solution incorporated in the power quality instrument above

\section{Conclusion}

Recent changes in standards and technology have made it possible to produce an IEC 61000-4-30 Class A power quality instrument at a very low cost. It is also small enough to be integrated into larger electrical equipment and control panels. 


\section{Biographies}

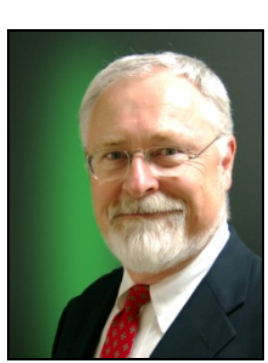

${ }^{1}$ Alex McEachern is well known for his cheerful, thought-provoking speeches, and he regularly speaks at national and international conferences on electric power quality. He is the president of Power Standards Lab in California, the founder of BMI, the former president of both BMI and Electrotek, and the author of everything from the Electric Power Measurements chapter of the Encyclopedia of Electrical and Electronics Engineering to the industry-standard Handbook of Power Signatures. Active in drafting and approving international power standards, Alex is the chairman of the International Electrotechnical Commission (IEC) TC77A Working Group 9, which sets the standard for power quality instruments. He also participates in the drafting of the voltage dip immunity standards, IEC 61000-4-11 and IEC 61000-4-34. $\mathrm{He}$ is a Senior Member of the IEEE, former Chairman of IEEE 1159.1, a co-author of IEEE 519 and IEEE 1459, and a voting member of the IEEE Standards Coordination Committee on Power.

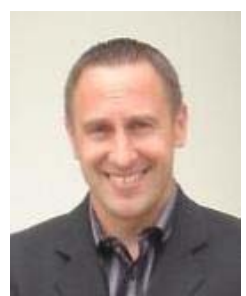

${ }^{2}$ Andreas Eberhard is well known in the international testing standard and power quality community. He is member of various power quality and safety standard committees around the world. He used to work for more than ten years with TUV Rheinland in Europe, Asia and the US before he joined Power Standards Lab in 2005. Andreas holds two Master Degrees (Electrical Engineering and Technology Management) from Universities in Europe and the United States. His latest work and studies are related to the impact of renewable energies on grid stability. With PSL he did develop and design a new Power Quality and Energy measurement technology. This innovative technology will improve and change the way how Power Quality and Energy was traditionally monitored. Andreas is also a co-author of the Intech Power Quality Book that was published in 2011.

He is Vice President of Technical Services at Power Standard Labs and can be contacted at aeberhard@powerstandards.com, or Tel ++1-510522-4400.

\section{Acknowledgement}

$\left.{ }^{\mathbf{1}}\right)$ The above-named main author (McEachern) is the Convenor of IEC TC77A Working Group 09, which is responsible for maintaining IEC 61000-430 Power Quality Measurement Methods. We gratefully acknowledge the useful and knowledgeable technical contributions of members of this Working Group during discussions and exchanges over the last 10 years. Any errors that remain in this paper are entirely the responsibility of the authors.

\section{Literature}

[1] IEC 61000-4-30, Ed 1, "Testing and Measurement Techniques - Power Quality Measurement Methods.” International Electrotechnical Commission. February 2003.

[2] Corrigendum 1, IEC 61000-4-30, Ed 1. August 2006.

[3] IEC 61000-4-15, Ed 1.1, "Flickermeter Functional and Design Specifications." International Electrotechnical Commission. 2003.

[4] IEC 61000-4-7, Ed 2, “General Guide on Harmonics and Interharmonics Measurements and Instrumentation.” International Electrotechnical Commission. 2002. 